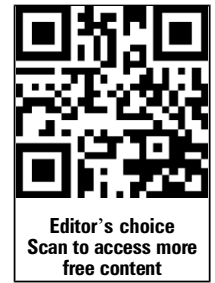

- Additional material is published online only. To view please visit the journal online (http://dx.doi.org/10.1136/ heartjnl-2013-303798).

For numbered affiliations see end of article.

Correspondence to Dr Marco V Perez, Stanford University Medical Center, Cardiac Electrophysiology and Arrhythmia Service, 300 Pasteur Drive \#H2146, Stanford, CA 94305, USA: mvperez@stanford.edu

Received 8 February 2013 Revised 14 May 2013 Accepted 14 May 2013 Published Online First 11 June 2013

\title{
Risk factors for atrial fibrillation and their population burden in postmenopausal women: the Women's Health Initiative Observational Study
}

\author{
Marco V Perez, ${ }^{1}$ Paul J Wang, ${ }^{1}$ Joseph C Larson, ${ }^{2}$ Elsayed Z Soliman, ${ }^{3}$ \\ Marian Limacher, ${ }^{4}$ Beatriz Rodriguez, ${ }^{5}$ Liviu Klein, ${ }^{6}$ JoAnn E Manson, ${ }^{7}$ \\ Lisa W Martin, ${ }^{8}$ Ronald Prineas, ${ }^{3}$ Stephanie Connelly, ${ }^{9}$ Mark Hlatky, ${ }^{1}$ \\ Sylvia Wassertheil-Smoller, ${ }^{10}$ Marcia L Stefanick ${ }^{11}$
}

\section{ABSTRACT \\ Objective Atrial fibrillation (AF) is the most common arrhythmia in women. Large studies evaluating key AF risk factors in older women are lacking. We aimed to identify risk factors for AF in postmenopausal women and measure population burden of modifiable risk \\ factors. \\ Design Prospective observational study. \\ Setting The Women's Health Initiative (WHI) \\ Observational Study.}

Patients 93676 postmenopausal women were followed for an average of 9.8 years for cardiovascular outcomes. After exclusion of women with prevalent AF or incomplete data, 8252 of the remaining 81892 women developed incident AF.

Main outcome measures Incident AF was identified by WHI-ascertained hospitalisation records and diagnosis codes from Medicare claims. Multivariate Cox hazard regression analysis identified independent risk factors for incident AF.

Results Age, hypertension, obesity, diabetes, myocardial infarction and heart failure were independently associated with incident AF. Hypertension and overweight status accounted for $28.3 \%$ and $12.1 \%$, respectively, of the population attributable risk. Hispanic and African-American participants had lower rates of incident AF (HR 0.58, 95\% Cl 0.47 to 0.70 and HR $0.59,95 \% \mathrm{Cl} 0.53$ to 0.65 , respectively) than Caucasians.

Conclusions Caucasian ethnicity, traditional cardiovascular risk factors and peripheral arterial disease were independently associated with higher rates of incident AF in postmenopausal women. Hypertension and overweight status accounted for a large proportion of population attributable risk. Measuring burden of modifiable AF risk factors in older women may help target interventions.

\section{INTRODUCTION}

Atrial fibrillation (AF), characterised by chaotic electrical activity in the atrium, remains the most common arrhythmia in adults, affecting over 2.2 million people in the USA, ${ }^{1}$ including up to $9.1 \%$ of women aged 85 years and older. ${ }^{2}$ AF accounts for approximately 75000 strokes per year ${ }^{3}$ and independently increases the risk of death by 1.5-1.9-fold. ${ }^{4}{ }^{5}$ Although $\mathrm{AF}$ rates are lower in women than men, ${ }^{2}$ women with $\mathrm{AF}$ are more likely to develop stroke ${ }^{3} 7$ and may be at a higher risk of death than men with AF. ${ }^{46}$

The aetiology and underlying pathophysiology of $\mathrm{AF}$ is poorly understood. Analyses of large prospective cohorts, including the Framingham Heart Study, ${ }^{8}$ the Cardiovascular Health Study $^{9}$ and others ${ }^{10} 11$ have identified the principal independent risk factors of AF including hypertension, diabetes mellitus, obesity, myocardial infarction, coronary heart disease (CHD) and heart failure; these analyses were summarised in a recent systematic review. ${ }^{12}$

Large studies assessing the population-wide, independent contribution of risk factors for incident AF in older women are limited. We therefore conducted this analysis in the multiethnic Women's Health Initiative (WHI) Observational Study (OS) cohort of 93676 postmenopausal women, one of the largest cohorts available with ascertainment of incident AF.

\section{METHODS}

Study population

The WHI-OS is a prospective observational cohort study of postmenopausal women aged between 50 and 79 at baseline, who were recruited at 40 US clinical centres to assess the relationship of various self-reported demographics, such as age, ethnicity, and medical and lifestyle factors on the risk of key health outcomes, such as cardiovascular diseases, including AF, over time. Details of the study design and methods have been previously reported. ${ }^{13-15}$ Briefly, participants were recruited, primarily through mass-mailings to age-eligible women, into either a set of clinical trials or the WHI-OS. Excluded were women who were not likely to survive or remain in the vicinity of a given WHI clinic for the next 3 years or who had alcoholism, drug dependency or dementia. A total of 93676 participants were enrolled between 1994 and 1998 .

\section{Study procedure}

Women completed baseline self- or intervieweradministered questionnaires for eligibility screening. Baseline characteristics, including demographic, reproductive and personal and family health history, were gathered. Physical examinations,
To cite: Perez MV,

Wang PJ, Larson JC, et al.

Heart 2013;99:1173-1178. 
including clinic height and weight measurements, and blood collections were performed at baseline and again at 3 years. Women were sent questionnaires annually to update their medical and lifestyle information. The study was reviewed and approved by the institutional review boards at each clinical centre, and all participants provided written informed consent.

\section{Definition of baseline variables and end points}

Details of study questionnaires, physical measurements, blood collection and quality assurance have been described previously. ${ }^{13-15}$ Race and ethnicity were self-reported in the baseline questionnaire, and women who reported a race or ethnicity other than black or Hispanic, such as Asian, Native American, Pacific Islander or other race, were categorised as 'Other'. Baseline AF was self-reported by questionnaire or documented by the presence of AF on a 12-lead ECG during the baseline clinic visit. Peripheral arterial disease (PAD) was ascertained on the baseline questionnaire by asking if the subject had ever been told by her doctor if she had 'claudication or PAD (poor blood flow to the legs or blocked or narrowed arteries to the legs)?'. Baseline questionnaires also assessed for a history of CHD, diabetes, hyperlipidaemia, heart failure and hypertension. In addition, blood pressure measurements at the initial clinic visit identified baseline hypertension, defined as elevated systolic $(\geq 140 \mathrm{~mm} \mathrm{Hg})$ or diastolic $(\geq 90 \mathrm{~mm} \mathrm{Hg})$ blood pressure. Overweight status was defined as a body mass index (BMI) $\geq 25 \mathrm{~kg} / \mathrm{m}^{2}$, and obese status was defined as BMI $\geq 30 \mathrm{~kg} / \mathrm{m}^{2}$.

Women were followed with medical history update questionnaires at years 3-8, which specifically probed for hospitalisations. Ascertainment of AF in WHI has been described previously. ${ }^{16}$ Medical records were obtained in the event of hospitalisation, and the International Classification of Disease-version 9 (ICD-9) code for AF (427.31) was extracted from these records. WHI data were linked with their Centers for Medicare and Medicaid Services (CMS) data using social security numbers, birth dates and death dates, with $97 \%$ of Medicare-eligible WHI participants successfully linked. Among participants with Medicare coverage, incident AF was identified by first occurrence of ICD-9 code 427.31 in any diagnosis position in the inpatient (MEDPAR), outpatient and carrier files during years 1994-2007. Because the Medicare data were available for some participants but not others at different time periods over WHI follow-up, a time-dependent indicator variable of Medicare coverage was added to the Cox hazard models described below to adjust for possible ascertainment bias related to differential exposure to CMS. Medicare time eligible for analysis included those intervals where participants were enrolled in fee-for-service Medicare and not simultaneously enrolled in a Medicare-managed care plan. Women with any single ICD-9 code of 427.31 from review of Medicare claims or hospital records were classified as having new-onset AF.

\section{Statistical analysis}

Baseline characteristics of participants with and without incident $\mathrm{AF}$ as well as different ethnicities were compared using either the Student $t$ test for continuous variables or the $\chi^{2}$ test for categorical variables. Assessment of risk factors for incident AF was performed using multivariate Cox hazard regression analysis. For this analysis, the 4397 participants with prevalent AF and 7833 participants with incomplete data were excluded. Multivariate analyses were performed using a primary model containing covariates with known or suspected association with AF including age, race/ethnicity, hypertension, diabetes, hyperlipidaemia, heart failure, myocardial infarction, coronary artery disease, PAD, BMI, smoking, alcohol use, hormone therapy use and level of education. A secondary multivariate model was created with a combined 'atherosclerotic burden' variable defined as PAD, stroke, prior myocardial infarction, coronary bypass surgery or percutaneous coronary angioplasty, and adjusted for all remaining factors from the primary multivariate model.

Associations were reported as HRs with 95\% CIs. The proportional hazards assumption was verified by testing the interaction of time and postmenopausal hormone therapy and through visual inspection of the log-likelihood plot of developing AF over time. Kaplan-Meier plots were drawn to depict the relationships between $\mathrm{PAD}$ or race/ethnicity and incident $\mathrm{AF}$. The population attributable risk (PAR) of each preventable or treatable risk factor was calculated as the difference between the rate of $\mathrm{AF}$ in the entire cohort minus the rate of $\mathrm{AF}$ in those who carried the risk factor, divided by the rate of AF in the entire cohort. Analyses were performed using SAS statistical software V.9.1.

\section{RESULTS}

\section{Baseline characteristics}

Of the 93676 women enrolled in the OS, 4397 (4.7\%) women were excluded because of self-reported baseline AF and 7833 (8.4\%) were excluded for missing data, leaving 81892 women available for analysis. Baseline characteristics of the study group, total and by self-reported race/ethnicity, are presented in table 1 , as are statistics for unadjusted differences among ethnic groups. On average, participants were 63 years of age, $42.4 \%$ had a history of hypertension, $2.0 \%$ reported PAD, $3.9 \%$ were selfreported diabetic, and $0.6 \%$ had a history of heart failure. Rates of AF increase significantly with age and are higher for women with CHD in all age groups (see online supplementary figure S1). The rate of incident AF in women between 75 and 80 years of age was $\sim 2.8 \% /$ year in the absence of CHD, and 4.9\%/year in women with CHD.

\section{Risk factors for incident AF}

Over an average of 9.8 years, 8252 participants developed newonset AF with an average annual incidence of $1.02 \%$, including 2021 cases identified only through WHI hospitalisation chart reviews, 4009 cases identified only through CMS coding, and 2222 identified by both methods.

Multivariate-adjusted Cox hazard regression analysis confirmed previous reports that socioeconomic factors, myocardial infarction and multiple cardiovascular risk factors, such as hypertension and diabetes, are independently associated with incident AF (table 2). Heart failure was the strongest independent predictor of incident $\mathrm{AF}$, with a more than twofold higher HR. Current and past tobacco use remained independently associated with incident AF, whereas hyperlipidaemia was not associated with AF after adjustment for other risk factors. Past but not current alcohol use was associated with incident AF. We also found that PAD was predictive of incident $\mathrm{AF}$ with a $\mathrm{HR}$ of 1.53 , independent of $\mathrm{CHD}$, hypertension or the other major cardiovascular risk factors (table 2). Each subgroup with baseline PAD studied, including participants with hypertension and $\mathrm{CHD}$, demonstrated an increased risk of developing $\mathrm{AF}$ (see online supplementary figure S2). A Kaplan-Meier plot comparing the cumulative hazard of $\mathrm{AF}$ in participants with and without PAD shows a significant separation of the curves $(\log -$ rank $\mathrm{p}<0.001)$ (figure $1 \mathrm{~A})$. In a sensitivity analysis, atherosclerotic burden, defined as presence of PAD, prior myocardial infarction, coronary bypass surgery or percutaneous coronary 
Table 1 Baseline characteristics by race/ethnicity, excluding women with baseline atrial fibrillation

\begin{tabular}{|c|c|c|c|c|c|c|}
\hline Characteristic & All participants $(n=81892)$ & Caucasian $(n=74321)$ & Black $(n=7234)$ & Hispanic $(n=3492)$ & Other $(n=4232)$ & p Value \\
\hline \multicolumn{7}{|l|}{ Demographics } \\
\hline Age, mean (SD) & $63.4(7.3)$ & $63.7(7.3)$ & $61.9(7.3)$ & $60.4(7.1)$ & $63.6(7.6)$ & $<0.001$ \\
\hline BMI $\left(\mathrm{kg} / \mathrm{m}^{2}\right)$, mean (SD) & $27.2(5.8)$ & $26.9(5.7)$ & $30.6(6.7)$ & $28.4(5.9)$ & $25.6(5.3)$ & $<0.001$ \\
\hline$<25$ & $33637(41.1)$ & $29513(42.9)$ & $1210(19.2)$ & $870(29.7)$ & $2044(53.1)$ & \\
\hline $25-<30$ & $27973(34.2)$ & $23465(34.1)$ & $2181(34.6)$ & $1122(38.3)$ & $1205(31.3)$ & \\
\hline $30-<35$ & $12726(15.5)$ & $10183(14.8)$ & 1549 (24.6) & $603(20.6)$ & $391(10.2)$ & \\
\hline $35-<40$ & $4748(5.8)$ & $3613(5.3)$ & 779 (12.4) & $227(7.8)$ & 129 (3.4) & \\
\hline$\geq 40$ & $2808(3.4)$ & $2045(3.0)$ & $576(9.2)$ & 106 (3.6) & $81(2.1)$ & \\
\hline Income & & & & & & $<0.001$ \\
\hline$<$ US\$20000 & $11550(14.1)$ & $8324(12.1)$ & $1726(27.4)$ & $890(30.4)$ & $610(15.8)$ & \\
\hline US\$20 000-49999 & $33060(40.4)$ & $28126(40.9)$ & $2418(38.4)$ & $1090(37.2)$ & $1426(37.0)$ & \\
\hline US\$50 000-74 999 & $15625(19.1)$ & $13487(19.6)$ & $1022(16.2)$ & $359(12.3)$ & $757(19.7)$ & \\
\hline$\geq$ US\$75000 & $15944(19.5)$ & $14270(20.7)$ & $635(10.1)$ & $275(9.4)$ & $764(19.8)$ & \\
\hline Education & & & & & & $<0.001$ \\
\hline$\leq$ High school/GED & $17089(20.9)$ & 13379 (19.4) & $1634(26.0)$ & $1157(39.5)$ & $919(23.9)$ & \\
\hline Some college & $29820(36.4)$ & $25032(36.4)$ & $2329(37.0)$ & $1083(37.0)$ & $1376(35.7)$ & \\
\hline College degree or higher & $34983(42.7)$ & $30408(44.2)$ & $2332(37.0)$ & $688(23.5)$ & $1555(40.4)$ & \\
\hline \multicolumn{7}{|l|}{ Medical history } \\
\hline Hypertension & & & & & & $<0.001$ \\
\hline Never treated & 47207 (57.6) & $41089(59.7)$ & $2250(35.7)$ & $1814(62.0)$ & $2054(53.4)$ & \\
\hline Currently untreated & 14475 (17.7) & 12001 (17.4) & $1167(18.5)$ & $525(17.9)$ & $782(20.3)$ & \\
\hline Treated & $20210(24.7)$ & $15729(22.9)$ & $2878(45.7)$ & $589(20.1)$ & $1014(26.3)$ & \\
\hline Diabetes mellitus & 3197 (3.9) & $1999(2.9)$ & $764(12.1)$ & $217(7.4)$ & $217(5.6)$ & $<0.001$ \\
\hline Hyperlipidaemia & 11909 (14.5) & $9647(14.0)$ & 1047 (16.6) & $484(16.5)$ & $731(19.0)$ & $<0.001$ \\
\hline Statin use at baseline & $6616(8.1)$ & $5483(8.0)$ & $545(8.7)$ & $205(7.0)$ & $383(9.9)$ & $<0.001$ \\
\hline CHD (MI/CABG/PTCA) & $2450(3.0)$ & $1996(2.9)$ & $278(4.4)$ & $62(2.1)$ & $114(3.0)$ & $<0.001$ \\
\hline $\mathrm{Ml}$ & $1678(2.0)$ & $1349(2.0)$ & $219(3.5)$ & $39(1.3)$ & $71(1.8)$ & $<0.001$ \\
\hline CABG/PTCA & $1437(1.8)$ & $1211(1.8)$ & $124(2.0)$ & $33(1.1)$ & $69(1.8)$ & $<0.001$ \\
\hline CVD (CHD/stroke) & $3353(4.1)$ & 2654 (3.9) & $426(6.8)$ & $110(3.8)$ & $163(4.2)$ & $<0.001$ \\
\hline Stroke & $1069(1.3)$ & $780(1.1)$ & $177(2.8)$ & $55(1.9)$ & $57(1.5)$ & $<0.001$ \\
\hline Heart failure & $514(0.6)$ & $375(0.5)$ & $96(1.5)$ & $21(0.7)$ & $22(0.6)$ & $<0.001$ \\
\hline Peripheral arterial disease & $1600(2.0)$ & $1253(1.8)$ & $209(3.3)$ & $71(2.4)$ & $67(1.7)$ & $<0.001$ \\
\hline Deep vein thrombosis & $2877(3.5)$ & $2533(3.7)$ & $195(3.1)$ & $63(2.2)$ & $86(2.2)$ & $<0.001$ \\
\hline Aspirin use at baseline & $16995(20.8)$ & $15239(22.1)$ & $874(13.9)$ & $329(11.2)$ & $553(14.4)$ & $<0.001$ \\
\hline Warfarin use at baseline & $444(0.5)$ & $381(0.6)$ & $40(0.6)$ & $10(0.3)$ & $13(0.3)$ & 0.126 \\
\hline Systolic BP, mean (SD) & $126.7(17.9)$ & $126.2(17.7)$ & $132.1(18.4)$ & $125.1(17.1)$ & $129.2(18.9)$ & $<0.001$ \\
\hline Diastolic BP, mean (SD) & $74.8(9.3)$ & $74.3(9.2)$ & $78.0(9.8)$ & $74.6(9.2)$ & $76.9(9.7)$ & $<0.001$ \\
\hline Heart rate, mean (SD) & $69.3(12.0)$ & $69.3(12.0)$ & $70.5(13.0)$ & $68.7(10.5)$ & $68.5(11.3)$ & $<0.001$ \\
\hline \multicolumn{7}{|l|}{ Habits } \\
\hline Smoking & & & & & & $<0.001$ \\
\hline Never & $41619(50.8)$ & $34044(49.5)$ & $3156(50.1)$ & $1842(62.9)$ & 2577 (66.9) & \\
\hline Past & $35194(43.0)$ & 30747 (44.7) & $2464(39.1)$ & $890(30.4)$ & 1093 (28.4) & \\
\hline Current & $5079(6.2)$ & $4028(5.9)$ & $675(10.7)$ & $196(6.7)$ & $180(4.7)$ & \\
\hline Alcohol & & & & & & $<0.001$ \\
\hline Never & $9044(11.0)$ & $6097(8.9)$ & 1174 (18.6) & $563(19.2)$ & $1210(31.4)$ & \\
\hline Past & $15066(18.4)$ & 11452 (16.6) & 2104 (33.4) & $700(23.9)$ & $810(21.0)$ & \\
\hline Current & $57782(70.6)$ & $51270(74.5)$ & 3017 (47.9) & $1665(56.9)$ & $1830(47.5)$ & \\
\hline
\end{tabular}

All values represent the total (percentage) unless otherwise indicated.

$\mathrm{BMI}$, body mass index; $\mathrm{BP}$, blood pressure; CABG, coronary artery bypass grafting; CHD, coronary heart disease; CVD, cardiovascular disease; GED, general educational development; MI, myocardial infarction; PTCA, percutaneous transluminal coronary angioplasty.

angioplasty, was predictive of AF with a HR of 1.63 (95\% CI 1.51 to 1.75 ). The PAR estimates of the most significant reversible or treatable risk factors from the multivariate model are presented in table 3 . The risk factor that contributed most to the population-wide risk of incident $\mathrm{AF}$ was hypertension $(\mathrm{PAR}=28.3 \%)$, followed by overweight or obese status $(\mathrm{PAR}=12.1 \%)$ (table 3$)$.

\section{Ethnicity/race and AF}

After exclusion of baseline AF, the WHI-OS cohort consisted of 7234 (8.8\%) African-American women, 3492 (4.3\%) Hispanic women, $421(0.45 \%)$ Asian/Pacific Islanders and 2671 (2.8\%) American-Indian women (Table 1). After adjustment for age, socioeconomic status and other cardiovascular risk factors, African-American women, Hispanic women and women of 
Table 2 Univariate and multivariate-adjusted HRs of incident atrial fibrillation for several demographic and clinical factors

\begin{tabular}{|c|c|c|c|c|c|c|}
\hline \multirow[b]{2}{*}{ Characteristic } & \multicolumn{2}{|l|}{ Unadjusted } & \multicolumn{2}{|c|}{ Age/ethnicity adjusted } & \multicolumn{2}{|c|}{ Multivariate adjusted } \\
\hline & $\mathrm{HR}(95 \% \mathrm{Cl})$ & $p$ Value & HR $(95 \% \mathrm{Cl})$ & $\mathrm{p}$ Value & $\mathrm{HR}(95 \% \mathrm{Cl})$ & $p$ Value \\
\hline Age (5 year increase) & 1.54 (1.51 to 1.56$)$ & $<0.001$ & 1.53 (1.50 to 1.56$)$ & $<0.001$ & 1.49 (1.47 to 1.52$)$ & $<0.001$ \\
\hline Race/ethnicity & & $<0.001$ & & $<0.001$ & & $<0.001$ \\
\hline White & 1.00 & & 1.00 & & 1.00 & \\
\hline African-American & 0.68 (0.61 to 0.76 ) & & 0.76 (0.69 to 0.85 ) & & 0.59 (0.53 to 0.65$)$ & \\
\hline Hispanic & 0.50 (0.41 to 0.61 ) & & 0.60 (0.49 to 0.73 ) & & 0.58 (0.47 to 0.70$)$ & \\
\hline Other & 0.67 (0.59 to 0.77 ) & & 0.66 (0.58 to 0.76 ) & & 0.67 (0.59 to 0.77$)$ & \\
\hline PAD & 2.37 (2.12 to 2.64 ) & $<0.001$ & 2.06 (1.85 to 2.30$)$ & $<0.001$ & 1.53 (1.37 to 1.72$)$ & $<0.001$ \\
\hline Hypertension & 1.83 (1.76 to 1.92 ) & $<0.001$ & 1.59 (1.52 to 1.67$)$ & $<0.001$ & 1.43 (1.36 to 1.50$)$ & $<0.001$ \\
\hline Diabetes & 2.08 (1.91 to 2.27 ) & $<0.001$ & 2.13 (1.95 to 2.33 ) & $<0.001$ & 1.55 (1.42 to 1.70$)$ & $<0.001$ \\
\hline Hyperlipidaemia & 1.28 (1.21 to 1.35$)$ & $<0.001$ & 1.16 (1.10 to 1.23$)$ & $<0.001$ & 0.95 (0.89 to 1.00$)$ & 0.069 \\
\hline Heart failure & 4.02 (3.42 to 4.73 ) & $<0.001$ & 3.65 (3.10 to 4.29$)$ & $<0.001$ & 2.19 (1.85 to 2.60$)$ & $<0.001$ \\
\hline Coronary heart disease & 2.84 (2.61 to 3.09 ) & $<0.001$ & 2.30 (2.12 to 2.51 ) & $<0.001$ & 1.76 (1.61 to 1.93$)$ & $<0.001$ \\
\hline BMI ( $5 \mathrm{~kg} / \mathrm{m}^{2}$ increase) & $1.13(1.11$ to 1.15$)$ & $<0.001$ & $1.18(1.16$ to 1.20$)$ & $<0.001$ & $1.12(1.10$ to 1.14$)$ & $<0.001$ \\
\hline PHT use ever & 0.87 (0.83 to 0.91 ) & $<0.001$ & 0.99 (0.94 to 1.03$)$ & 0.510 & 1.03 (0.98 to 1.07 ) & 0.285 \\
\hline Smoking & & $<0.001$ & & $<0.001$ & & $<0.001$ \\
\hline Never & 1.00 & & 1.00 & & 1.00 & \\
\hline Past & 1.15 (1.10 to 1.20$)$ & & 1.20 (1.15 to 1.25$)$ & & 1.18 (1.13 to 1.24$)$ & \\
\hline Current & 1.08 (0.98 to 1.20$)$ & & 1.31 (1.18 to 1.44 ) & & 1.32 (1.19 to 1.46$)$ & \\
\hline Alcohol use & & $<0.001$ & & $<0.001$ & & 0.006 \\
\hline Non-drinker & 1.00 & & 1.00 & & 1.00 & \\
\hline Past & 1.17 (1.08 to 1.27 ) & & 1.22 (1.12 to 1.32$)$ & & 1.09 (1.00 to 1.18$)$ & \\
\hline Current & 0.94 (0.88 to 1.01 ) & & $0.98(0.92$ to 1.06$)$ & & 1.00 (0.93 to 1.07$)$ & \\
\hline Education & & $<0.001$ & & $<0.001$ & & 0.004 \\
\hline$\leq$ High school/GED & 1.00 & & 1.00 & & 1.00 & \\
\hline Some college & 0.89 (0.84 to 0.94 ) & & 0.91 (0.86 to 0.96 ) & & 0.94 (0.88 to 0.99$)$ & \\
\hline College degree or higher & 0.76 (0.71 to 0.80$)$ & & 0.81 (0.77 to 0.86 ) & & 0.91 (0.86 to 0.96$)$ & \\
\hline
\end{tabular}

All demographic and clinical characteristics listed in the first column were included in the multivariate model.

BMI, body mass index; GED, general educational development; HR, Cox HR; PAD, peripheral arterial disease; PHT, postmenopausal hormone therapy.

other ethnicities were less likely to develop AF when compared with Caucasians (table 2). A Kaplan-Meier plot comparing the cumulative hazard of AF in participants of different ethnicities shows a significant separation of the curves $(\log$-rank $\mathrm{p}<0.001)$ (figure 1B).

\section{DISCUSSION}

In this large multiethnic, postmenopausal cohort, women developed $\mathrm{AF}$ at an average rate of $1.02 \%$ per year, with age-matched rates that were comparable to those reported in prior studies that used Medicare data for AF ascertainment. ${ }^{12}{ }^{17}$ Risk factors that have been established in other large cohort studies, ${ }^{8-12}$ including hypertension, CHD, diabetes and heart failure, were also associated with AF in the WHI cohort. Hypertension and obesity, important modifiable risk factors, contributed significantly to the population risk. In addition, independent of these well-established risk factors, PAD and ethnicity were associated with incident AF. Although others have reported a correlation between $\mathrm{PAD}$ and prevalent $\mathrm{AF}^{18}{ }^{19}$ or subclinical atherosclerosis and incident $\mathrm{AF}$, none of the previous large cohort studies ${ }^{8-11}$ evaluated the independent relationship between PAD and incident AF.

Higher BMI was significantly associated with incident AF independent of diabetes mellitus, coronary disease or other major cardiovascular risk factors, with a $17 \%$ increased risk for every $5 \mathrm{~kg} / \mathrm{m}^{2}$. Obesity has been previously described as an important risk factor for $\mathrm{AF}^{20}{ }^{21}$ and the effects may be mediated through increased left atrial size ${ }^{20}$ or presence of pericardial fat. ${ }^{22}$ Studies from the Framingham ${ }^{8}$ and Atherosclerosis
Risk in Communities (ARIC) ${ }^{23}$ cohorts are the only other large population-based studies that have reported the burden of disease attributed to modifiable risk factors. We report that, in older women, overweight status or obesity accounted for an alarmingly high PAR (12.1\%), second only to hypertension. Similarly, in the ARIC cohort, obesity accounted for $12.7 \%$ of the PAR. ${ }^{23}$ Given the obesity epidemic, this is yet another reason more attention should be paid to population-based efforts to control obesity and to further study the mechanisms linking obesity and AF.

Although the links between PAD and coronary or cerebral vascular disease are well established, it is less clear why PAD is independently associated with AF. PAD was determined by selfreport at baseline and therefore may represent a subset of women with a heavier burden of atherosclerotic disease. Further studies are needed to examine the role of PAD in modulating the risk of $\mathrm{AF}$ itself.

We and other population studies ${ }^{2}{ }^{24}$ have found that rates of incident $\mathrm{AF}$ are lower in African-Americans than Caucasians, suggesting possible underlying environmental or genetic risk factors related to race. Previous studies in veteran male populations where different race groups had similar access to healthcare reported similar findings. ${ }^{25} 26$ These differences persist despite adjustment for socioeconomic factors. In admixture studies of African-Americans, European ancestry is associated with $\mathrm{AF}$ in cohorts containing men and women. ${ }^{27}$ Further studies will be necessary to better determine how much of the difference in rates of AF is accounted for by genomic ancestry versus differential environmental exposures. 
Figure 1 (A) Cumulative hazard of atrial fibrillation (AF) by baseline peripheral arterial disease (PAD) status.

(B) Cumulative hazard of AF by ethnicity. Access the article online to view this figure in colour. (a)

AF by Ethnicity

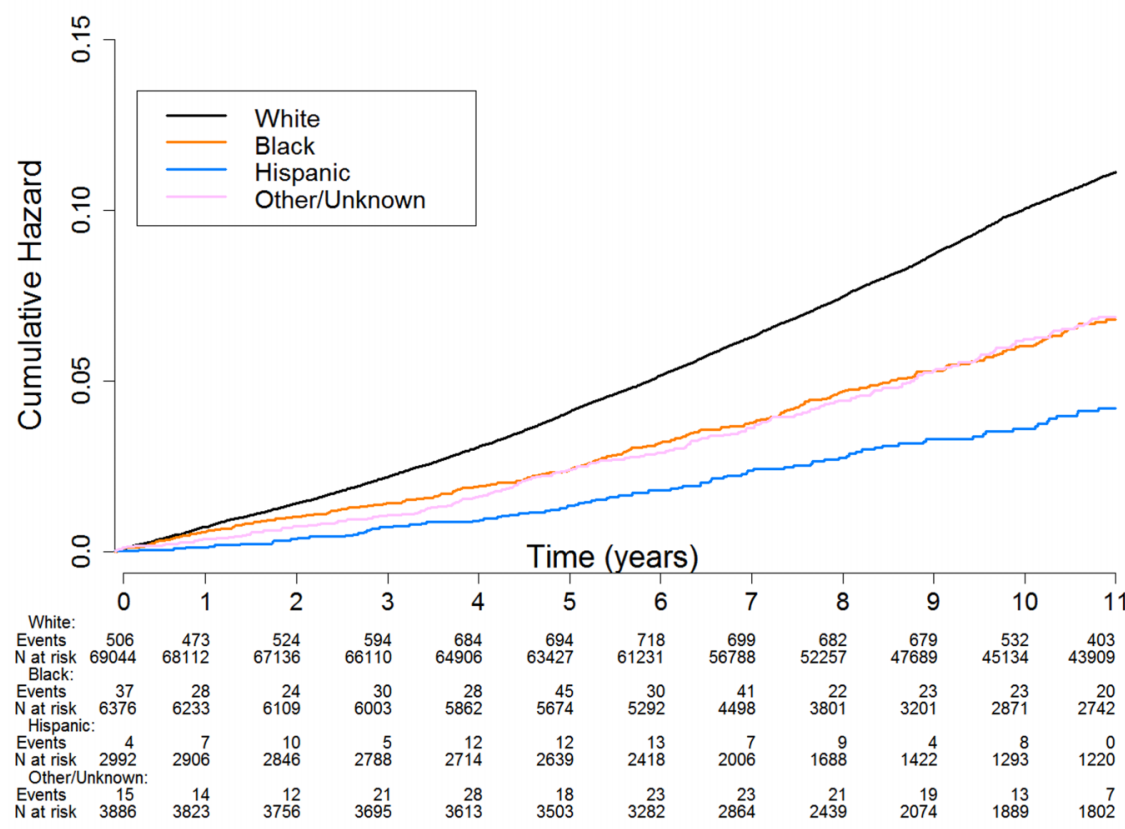

(b)

\section{AF by Baseline PAD}

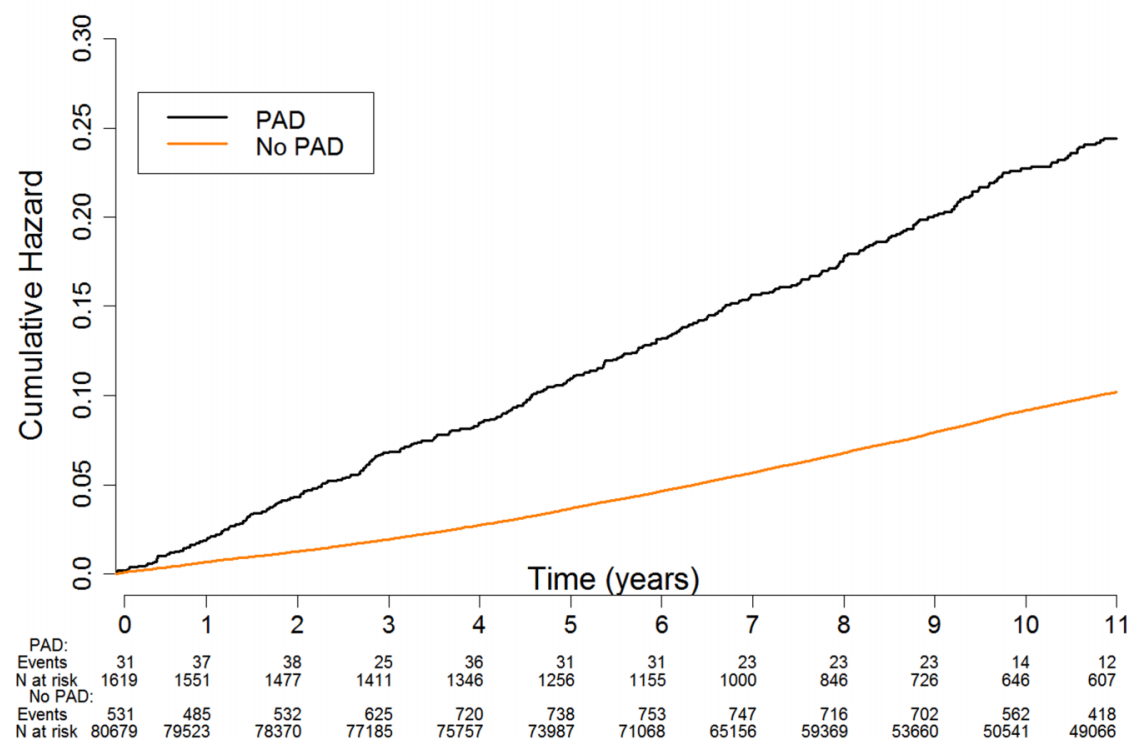

Table 3 Population attributable risk (PAR) of reversible or treatable risk factors of atrial fibrillation

\begin{tabular}{lr}
\hline Characteristic & PAR\% \\
\hline Hypertension & 28.3 \\
Overweight or obese & 12.1 \\
Diabetes mellitus & 3.4 \\
Past smoking & 5.9 \\
Past alcohol use & 3.8 \\
Peripheral arterial disease & 2.5 \\
Heart failure & 1.4 \\
Coronary heart disease & 4.7 \\
No college education & 4.4 \\
\hline
\end{tabular}

PAR\%, [(total rate-unaffected annualised rate)/(total rate) $] \times 100$.

Overweight or obese, body mass index $\geq 25$.
We have previously reported details of the methods used to link WHI participants to their Medicare claims records and ascertain incident $\mathrm{AF}^{16}$ Approximately 98\% of incident cases identified by WHI ECG or ICD-9 coding from hospitalisation in women enrolled in Medicare at the time were identified through CMS linkage. ICD-9 codes for identification of AF have been used by several large population-based cohorts. ${ }^{2} 924$ The use of ICD-9 coding to correctly identify incident AF has been validated in several large population-based cohorts, ${ }^{2} 924$ with a median positive predictive value of $89 \%,,^{24-31}$ as detailed further in a recent systematic review. ${ }^{32}$ Our previous sensitivity analyses using stricter definitions of incident AF did not significantly change our findings. ${ }^{16}$ We found that HR estimates using Medicare ascertainment alone were similar to those found using WHI ascertainment (data not shown). Nevertheless, AF can be asymptomatic and paroxysmal, making 
the diagnosis difficult in a subgroup of women. Although there is a potential for misclassification regardless of the definition used, the biases introduced would generally be non-differential, probably resulting in dilution of associations towards the null.

In summary, we found that PAD was a significant risk factor for incident $\mathrm{AF}$ in postmenopausal women, independent of other cardiovascular diseases and risk factors, and that hypertension and obesity together accounted for over one-third of the PAR for AF. We also report that, compared with Caucasian women, African-American and Hispanic women are protected from developing AF, independent of socioeconomic and cardiovascular risk factors. Further studies that explore the link between vascular disease, obesity and AF are warranted.

\author{
Author affiliations \\ ${ }^{1}$ Division of Cardiovascular Medicine, Department of Medicine, Stanford University, \\ Stanford, California, USA \\ ${ }^{2}$ Data Coordinating Center, Fred Hutchinson Cancer Research Center, Seattle, \\ Washington, USA \\ ${ }^{3}$ Departments of Epidemiology, Prevention and Internal Medicine, Section on \\ Cardiology, Wake Forest School of Medicine, Epidemiological Cardiology Research \\ Center (EPICARE), Winston Salem, North Carolina, USA \\ ${ }^{4}$ Division of Cardiovascular Medicine, Department of Medicine, University of Florida, \\ Gainesville, Florida, USA \\ ${ }^{5}$ Departments of Geriatric Medicine and Epidemiology, University of Hawaii, \\ Honolulu, Hawaii, USA \\ ${ }^{6}$ Department of Medicine, University of California San Francisco, San Francisco, \\ California, USA \\ ${ }^{7}$ Division of Preventive Medicine, Department of Medicine, Brigham and Women's \\ Hospital and Harvard Medical School, Boston, Massachusetts, USA \\ ${ }^{8}$ Division of Cardiology, Department of Medicine, George Washington University, \\ Washington, District of Columbia, USA \\ ${ }^{9}$ Department of Medicine, University of Tennessee, Knoxville, Tennessee, USA \\ ${ }^{10}$ Department of Epidemiology and Population Health, Albert Einstein College of \\ Medicine, Bronx, New York, USA \\ ${ }^{11}$ Department of Medicine, Stanford Prevention Research Center, Stanford University,
} Stanford, California, USA

Acknowledgements A full listing of Women's Health Initiative investigators can be found at http://whiscience.org/publications/WHI_investigators_longlist. We thank the Women's Health Initiative investigators, staff and study participants for their outstanding dedication and commitment.

Contributors All authors were involved in study conception and design, interpretation of data, and drafting and/or editing of the article. All authors have approved the version of the manuscript to be published.

Funding This project was supported by the American Heart Association Fellow to Faculty award 11FTF7260019. The WHI program is funded by the National Heart, Lung, and Blood Institute, National Institutes of Health, US Department of Health and Human Services through contracts HHSN268201100046C HHSN268201100001C, HHSN268201100002C, HHSN268201100003C, HHSN268201100004C and HHSN271201100004C.

Competing interests None.

Patient consent Obtained.

Ethics approval Ethics approval was obtained from the Stanford University IRB.

Provenance and peer review Not commissioned; externally peer reviewed.

\section{REFERENCES}

1 Feinberg WM, Blackshear JL, Laupacis $A$, et al. Prevalence, age distribution, and gender of patients with atrial fibrillation. Analysis and implications. Arch Intern Med 1995; 155:469-73.

2 Go AS, Hylek EM, Phillips KA, et al. Prevalence of diagnosed atrial fibrillation in adults: national implications for rhythm management and stroke prevention: the AnTicoagulation and Risk Factors in Atrial Fibrillation (ATRIA) Study. JAMA 2001;285:2370-5

3 Wolf PA, Mitchell JB, Baker CS, et al. Impact of atrial fibrillation on mortality, stroke, and medical costs. Arch Intern Med 1998;158:229-34.
4 Benjamin EJ, Wolf PA, D'Agostino RB, et al. Impact of atrial fibrillation on the risk of death: the Framingham Heart Study. Circulation 1998;98:946-52.

5 Conen D, Chae CU, Glynn RJ, et al. Risk of death and cardiovascular events in initially healthy women with new-onset atrial fibrillation. JAMA 2011;305:2080-7.

6 Friberg J, Scharling H, Gadsboll N, et al. Comparison of the impact of atrial fibrillation on the risk of stroke and cardiovascular death in women versus men (The Copenhagen City Heart Study). Am J Cardiol 2004;94:889-94.

7 Avgil Tsadok M, Jackevicius CA, Rahme E, et al. Sex differences in stroke risk among older patients with recently diagnosed atrial fibrillation. JAMA 2012;307:1952-8.

8 Benjamin EJ, Levy D, Vaziri SM, et al. Independent risk factors for atrial fibrillation in a population-based cohort. The Framingham Heart Study. JAMA 1994;271:840-4.

9 Psaty BM, Manolio TA, Kuller LH, et al. Incidence of and risk factors for atrial fibrillation in older adults. Circulation 1997;96:2455-61.

10 Stewart S, Hart CL, Hole DJ, et al. Population prevalence, incidence, and predictors of atrial fibrillation in the Renfrew/Paisley study. Heart 2001;86:516-21.

11 Krahn AD, Manfreda J, Tate RB, et al. The natural history of atrial fibrillation: incidence, risk factors, and prognosis in the Manitoba Follow-Up Study. Am J Med 1995:98:476-84

12 Ball J, Carrington MJ, McMurray JJ, et al. Atrial fibrillation: Profile and burden of an evolving epidemic in the 21st century. Int J Cardiol 2013.

13 Anderson G, Cummings S, Freedman LS, et al. Design of the Women's Health Initiative clinical trial and observational study. The Women's Health Initiative Study Group. Control Clin Trials 1998;19:61-109.

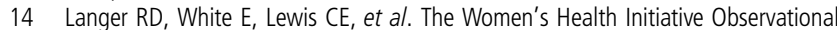
Study: baseline characteristics of participants and reliability of baseline measures. Ann Epidemiol 2003;13(9 Suppl):S107-21.

15 Curb JD, McTiernan A, Heckbert SR, et al. Outcomes ascertainment and adjudication methods in the Women's Health Initiative. Ann Epidemiol 2003;13(9 Suppl):S122-8.

16 Perez MV, Wang PJ, Larson JC, et al. Effects of postmenopausal hormone therapy on incident atrial fibrillation: the women's health initiative randomized controlled trials. Circ Arrhythm Electrophysiol 2012;5:1108-16.

17 Piccini JP, Hammill BG, Sinner MF, et al. Incidence and prevalence of atrial fibrillation and associated mortality among Medicare beneficiaries, 1993-2007. Circ Cardiovasc Qual Outcomes 2012;5:85-93.

18 Goto S, Bhatt DL, Rother J, et al. Prevalence, clinical profile, and cardiovascular outcomes of atrial fibrillation patients with atherothrombosis. Am Heart $J$ 2008;156:855-63, 63 e2.

19 Conway DS, Lip GY. Comparison of outcomes of patients with symptomatic peripheral artery disease with and without atrial fibrillation (the West Birmingham Atrial Fibrillation Project). Am J Cardiol 2004;93:1422-5, A10.

20 Wang TJ, Parise $H$, Levy $D$, et al. Obesity and the risk of new-onset atrial fibrillation. JAMA 2004:292:2471-7.

21 Gami AS, Hodge DO, Herges RM, et al. Obstructive sleep apnea, obesity, and the risk of incident atrial fibrillation. J Am Coll Cardiol 2007;49:565-71.

22 Thanassoulis G, Massaro JM, O'Donnell CJ, et al. Pericardial fat is associated with prevalent atrial fibrillation: the Framingham Heart Study. Circ Arrhythm Electrophysiol 2010;3:345-50.

23 Huxley RR, Lopez FL, Folsom AR, et al. Absolute and attributable risks of atrial fibrillation in relation to optimal and borderline risk factors: the Atherosclerosis Risk in Communities (ARIC) study. Circulation 2011;123:1501-8.

24 Alonso A, Agarwal SK, Soliman EZ, et al. Incidence of atrial fibrillation in whites and African-Americans: the Atherosclerosis Risk in Communities (ARIC) study. Am Heart J 2009;158:111-17.

25 Borzecki AM, Bridgers DK, Liebschutz JM, et al. Racial differences in the prevalence of atrial fibrillation among males. J Natl Med Assoc 2008;100:237-45.

26 Perez MV, Yaw TS, Myers J, et al. Prognostic value of the computerized ECG in Hispanics. Clin Cardiol 2007;30:189-94.

27 Marcus GM, Alonso A, Peralta CA, et al. European ancestry as a risk factor for atrial fibrillation in African Americans. Circulation 2011;122:2009-15.

28 Brass LM, Krumholz HM, Scinto JM, et al. Warfarin use among patients with atrial fibrillation. Stroke 1997;28:2382-9.

29 Shen AY, Yao JF, Brar SS, et al. Racial/ethnic differences in ischemic stroke rates and the efficacy of warfarin among patients with atrial fibrillation. Stroke 2008:39:2736-43.

30 Shireman TI, Howard PA, Kresowik TF, et al. Combined anticoagulant-antiplatelet use and major bleeding events in elderly atrial fibrillation patients. Stroke 2004;35:2362-7.

31 Whittle J, Wickenheiser L, Venditti LN. Is warfarin underused in the treatment of elderly persons with atrial fibrillation? Arch Intern Med 1997;157:441-5.

32 Jensen PN, Johnson K, Floyd J, et al. A systematic review of validated methods for identifying atrial fibrillation using administrative data. Pharmacoepidemiol Drug Saf 2012;21(Suppl 1):141-7 